archives

of thermodynamics

Vol. 37(2016), No. 2, 23-40

DOI: $10.1515 /$ aoter-2016-0011

\title{
Effect of nanofluid concentration on two-phase thermosyphon heat exchanger performance
}

\section{JANUSZ T. CIEŚLIŃSKI*}

Gdańsk University of Technology, Faculty of mMechanical Engineering, Department of Energy and Industrial Apparatus, 80-233 Gdańsk, Narutowicza 11/12, Poland

\begin{abstract}
An approach - relaying on application of nanofluid as a working fluid, to improve performance of the two-phase thermosyphon heat exchanger (TPTHEx) has been proposed. The prototype heat exchanger consists of two horizontal cylindrical vessels connected by two risers and a downcomer. Tube bundles placed in the lower and upper cylinders work as an evaporator and a condenser, respectively. Distilled water and nanofluid water- $\mathrm{Al}_{2} \mathrm{O}_{3}$ solution were used as working fluids. Nanoparticles were tested at the concentration of $0.01 \%$ and $0.1 \%$ by weight. A modified Peclet equation and Wilson method were used to estimate the overall heat transfer coefficient of the tested TPTHEx. The obtained results indicate better performance of the TPTHEx with nanofluids as working fluid compared to distilled water, independent of nanoparticle concentration tested. However, increase in nanoparticle concentration results in overall heat transfer coefficient decrease of the TPTHEx examined. It has been observed that, independent of nanoparticle concentration tested, decrease in operating pressure results in evaporation heat transfer coefficient increase.
\end{abstract}

Keywords: Two-phase thermosyphon; Heat exchanger; Nanofluid; Wilson method

\section{Nomenclature}

$$
\begin{array}{ll}
A & - \text { heat transfer area, } \mathrm{m}^{2} \\
C_{1}, C_{2}, C_{3} & - \text { Wilson method constant } \\
c_{p} & - \text { specific heat, } \mathrm{J} /(\mathrm{kgK}) \\
d & - \text { diameter, } \mathrm{m}
\end{array}
$$

${ }^{*}$ E-mail: jcieslin@pg.gda.pl 


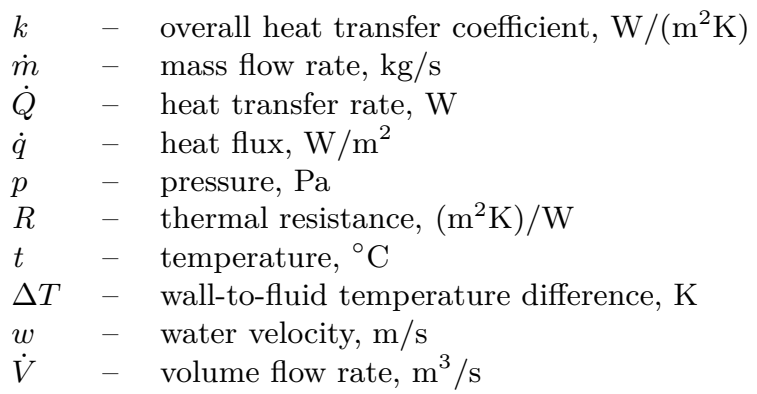

Greek symbols

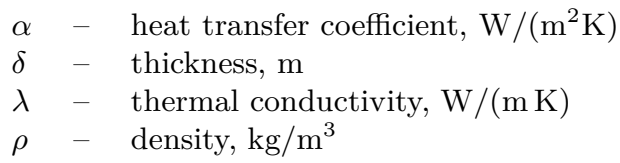

\section{Subscripts and superscripts}

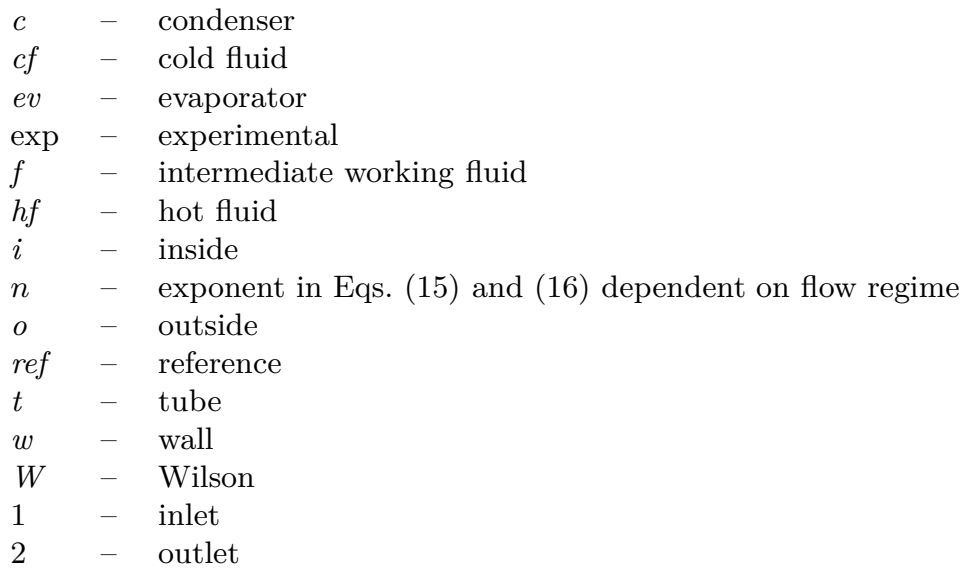

\section{Introduction}

Two-phase thermosyphon heat exchangers (TPTHEx) are used in a variety of heat engineering applications, but mechanisms governing the heat transfer process in such heat exchangers with shell-side boiling and condensation are far from complete understanding. The characteristic feature of a TPTHEx is that it operates as a thermal diode, it means that the heat can be transported only in one direction - from the evaporator to the condenser. Two-phase thermosyphons can be divided into two main groups: a termosyphon tube with countercurrent flow of the liquid and the vapour and a two-phase loop where the evaporator is connected to the 
condenser by a riser and downcomer [1-3]. Different aspects of two-phase thermosyphons performance have been investigated. Zhang et al. [4] established that the two-phase thermosyphon with a grooved evaporation surface has a much better performance due to the increased heat transfer at the evaporation surface. Khodabandeh and Furberg [5] found that the structured surface decreased the oscillations at the entire range of heat fluxes and enhanced the heat transfer coefficient of a thermosyphon loop with R134a as a working fluid. He et al. [6] studied the effect of noncondensable gases on steady-state and startup of a loop thermosyphon. Kafeel and Turan [7] analyzed numerically a vertical two phase closed thermosyphon. Results obtained show in detail the overall thermal response of the thermosyphon along with the dynamics of fluid flow within its core.

Quite new possibility of heat transfer augmentation gives addition of small amount of nanoparticles to the base liquid obtaining nanofluid new category of liquids developed at Argonne National Laboratory [8]. Nanofluid is a suspension consisting of the base liquid and metallic or nonmetallic nanoparticles with a typical size less than $100 \mathrm{~nm}$. The augment of thermal conductivity provides a basis for single phase heat transfer intensification (e.g., [9]). As regards pool boiling heat transfer mechanism important from the point of view of present study, contradictory statements can be found in the open literature. Some studies report no change of heat transfer in the nucleate boiling regime, some report heat transfer deterioration and others heat transfer enhancement e.g. [10]. Contrary to boiling heat transfer of nanofluids experimental data concerning heat transfer during condensation of nanofluids are very scarce. Huminic G. and Huminic A. [11] recorded heat transfer enhancement during condensation of water-iron oxide nanofluid at the condenser section of two-phase closed thermosyphon, independent of the inclination angle. However, according to Yang and Liu [12] the changes of the thermophysical properties have no meaningful effect on the condensing heat transfer coefficient of nanofluids and for vertical walls condensing heat transfer coefficient of nanofluids is well predicted by the well-known Nusselt correlation.

Utilization of nanofluids as working fluids in thermosyphons seems to be one of their obvious applications. However, literature data are very scarce. Xue et al. [13] observed that application of water-carbon nanotube (CNT) nanofluid as working fluid in simple tube thermosyphon (STT) resulted in the deterioration of its performance. The carbon nanotubes were treated by a nitric/silfuric acid mixture and the volume concentration of the suspen- 
sion was 1\%. Mehta and Khandekar [14] and Khandekar et al. [15] tested STT filled with water- $\mathrm{Al}_{2} \mathrm{O}_{3}$, water-CuO and water-laponite nanofluids. The mass concentration of the nanoparticles was $1 \%$. It was established that thermal performance was deteriorated when nanofluids were used as working fluid. Maximum deterioration was observed with laponite while minimum inhibition was for alumina particles based nanofluids. Contrary to Xue et al. [13] and Khandekar et al. [15], Noie et al. [16] established that the efficiency of STT increased up to $14.7 \%$ when water- $\mathrm{Al}_{2} \mathrm{O}_{3}$ nanofliud was applied as a working fluid. Furthermore, the efficiency of the tested STT increased with nanoparticle concentration increase. The volume concentration of the nanoparticles ranged from $1 \%$ to $3 \%$. Liu et al. [17] examined a miniature thermosyphon (of $6 \mathrm{~mm}$ internal diameter and $350 \mathrm{~mm}$ long), charged with water-CNT nanofluids of different carbon nanotube (CNT) concentrations (1.0-2.0wt\%). The results show that water-CNT nanofluids augment the performance of the thermosyphon and maximum heat transfer enhancement was achieved for $2 \% \mathrm{CNT}$ concentration. Furthermore, the heat transfer enhancement effect of water-CNT nanofluids increases with the decrease of the operation pressure $(20-7.4 \mathrm{kPa})$. Paramatthanuwat et al. $[18,19]$ studied influence of the filling ratio $(30 \%, 50 \%$, and $80 \%$ by evaporator length) and aspect ratio $(5,10$, and 20$)$ on performance of STT with water-Ag nanofluid as working fluid. The weight concentration of the nanoparticles was $0.5 \%$. It was found that the filling ratio has no effect on heat transfer characteristics and the heat transfer rate - using nanofluids, at all filling ratios, was higher than with pure water. Huminic G. and Huminic A. [11] and Huminic et al. [20] revealed that independent of inclination angle $\left(30^{\circ}, 45^{\circ}, 60^{\circ}\right.$ and $\left.90^{\circ}\right)$ application of water-iron oxide nanofluids improves performance of thermosyphon heat pipe. The volume concentration of the nanoparticles was equal to $2 \%$ and $5.3 \%$. Furthermore, the heat transfer rate increased with nanoparticle concentration increase. Firouzfar et al. [21] established that application of methanol-silver nanofluid as working fluid in TPTHEx leads to energy saving around $9-31 \%$ for cooling and $18-100 \%$ for reheating the supply air stream in an air conditioning system. Yang and Liu [12] tested rectangular plate thermosyphon made of copper. As working fluid water-SiO $\mathrm{S}_{2}$ nanofluids were applied. A silane of trimethyoxysilane was used to fabricate stable (functionalized) nanofluid. The weight concentration of the nanoparticles ranged from $0.5 \%$ to $2.5 \%$. The experiment was carried out at three steady operating pressures of $7.38,15.75$, and $31.18 \mathrm{kPa}$. No meaningful effect was 
found for the heat transfer of nanofluids in the examined thermosyphon. Recently, Buschmann [22] overviewed the very limited results of the application of nanofluids in thermosyphons, heat pipes, and oscillating heat pipes. Additionally, possible mechanisms for improvement of the thermal performance of these devices were discussed.

The purpose of the present study was to examine the influence of the concentration of the alumina $\left(\mathrm{Al}_{2} \mathrm{O}_{3}\right)$ nanoparticles and operating pressure inside the shell on the overall performance of a two-phase thermosyphon heat exchanger. Nanoparticles were tested at the concentration of $0.01 \%$ and $0.1 \%$ by weight. A modified Wilson method was used to reduce the experimental data. Moreover, the modified Peclet equation was applied to estimate the overall heat transfer coefficient of the tested TPTHEx.

\section{Experiments}

\subsection{Experimental setup}

The test stand consists of three main systems: prototype TPTHEx and heating and cooling water loops. The test facility is capable of determining of the overall heat transfer coefficient of TPTHEx. A schematic diagram of the test stand is shown in Fig. 1. Heating and cooling water loops contain a centrifugal pump, a flowmeter and a vent tank, each. A district heating network and a cooling tower are used as a heat source and heat sink, respectively. Heating and cooling water flow rates are controlled by regulating valves and are measured by the magnetic flowmeters Danfoss MAG 3100 accurate to $\pm 0.25 \%$. The average temperature of heating and cooling water at the inlet and outlet of the evaporator and condenser tube bundles of TPTHEx is measured by the resistance temperature devices Pt100 produced by Siemens with an accuracy of $\pm 0.1 \mathrm{~K}$.

\subsection{Prototype two-phase thermosyphon heat exchanger}

The prototype heat exchanger consists of two horizontal cylindrical vessels of $159 \mathrm{~mm}$ in diameter and of $1 \mathrm{~m}$ long connected by two risers and a downcomer [23]. Tube bundles placed in the lower and upper cylinder work as an evaporator and a condenser, respectively (Fig. 2). Evaporator is designed as a tube bundle consisted of 19 smooth tubes of $10 \mathrm{~mm}$ outer diameter (OD) with triangular arrangement and a pitch equal to 2.0 diameter (d). Condenser is designed as a tube bundle consisted of 31 smooth stainless 


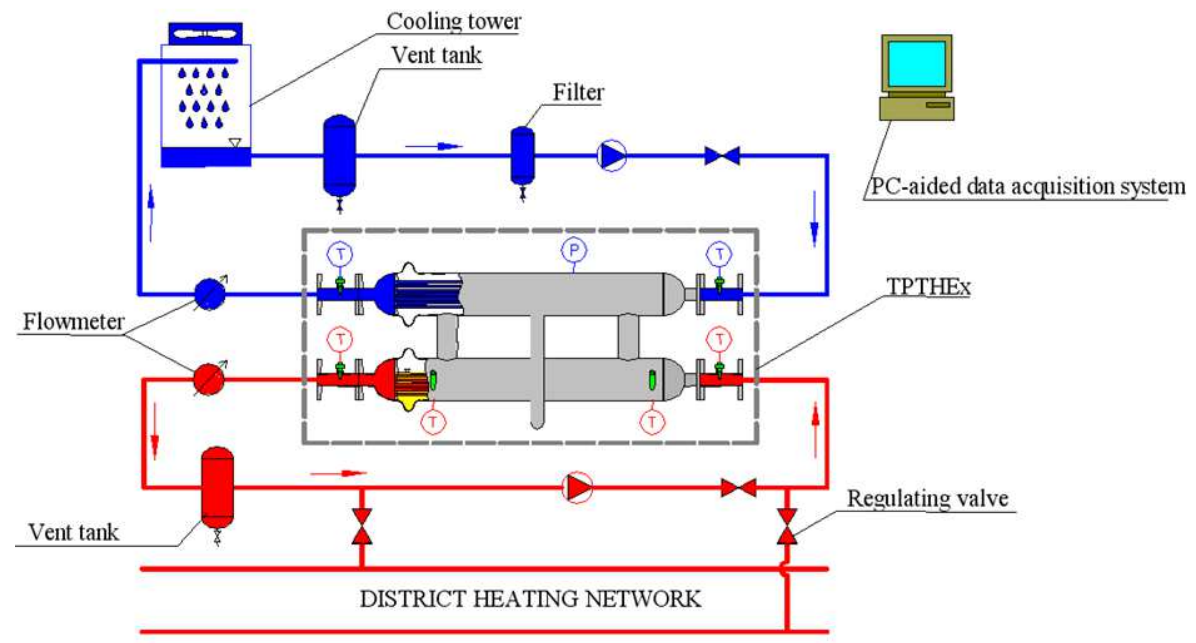

Figure 1: Schematic view of the experimental setup: $T$ - temperature sensor, $P$ - pressure sensor.

steel tubes (OD $10 \mathrm{~mm}$ ) with triangular arrangement and a pitch equal to $1.8 \mathrm{~d}$. Figure 3 illustrates flow of liquid and vapour in prototype TPTHEx against evaporator heat flux.

\subsection{Preparation and characterization of the tested nanofluids}

In the present study $\mathrm{Al}_{2} \mathrm{O}_{3}$ was applied as nanoparticles while distilled, deionized water was used as a base fluid. Nanofluids with two concentrations were prepared for the experiments. Alumina $\left(\mathrm{Al}_{2} \mathrm{O}_{3}\right)$ nanoparticles were tested at the concentration of $0.01 \%$ and $0.1 \%$ by weight. Nanoparticles of the required amount and base fluid were mixed together. Alumina nanoparticles of spherical form have diameter from $5 \mathrm{~nm}$ to $250 \mathrm{~nm}$; their mean diameter was estimated to be $47 \mathrm{~nm}$ according to the manufacturer (Sigma-Aldrich Co.). Tested nanofluids were prepared in two steps. First, ultrasonic vibration was used for $4 \mathrm{~h}$ in order to obtain concentrated solution that was next mixed with distilled, deionized water by use of homogenizer for $1 \mathrm{~h}$. The measured $\mathrm{pH}$ values for $\mathrm{Al}_{2} \mathrm{O}_{3}$ nanofluids with nanoparticle concentration of $0.01 \%$, and $0.1 \%$ were 6.51 and 7.48 , respectively. The stability of the produced nanofluids was pretty good, which can stay for a few days without visually observable sedimentation. Figure 4 


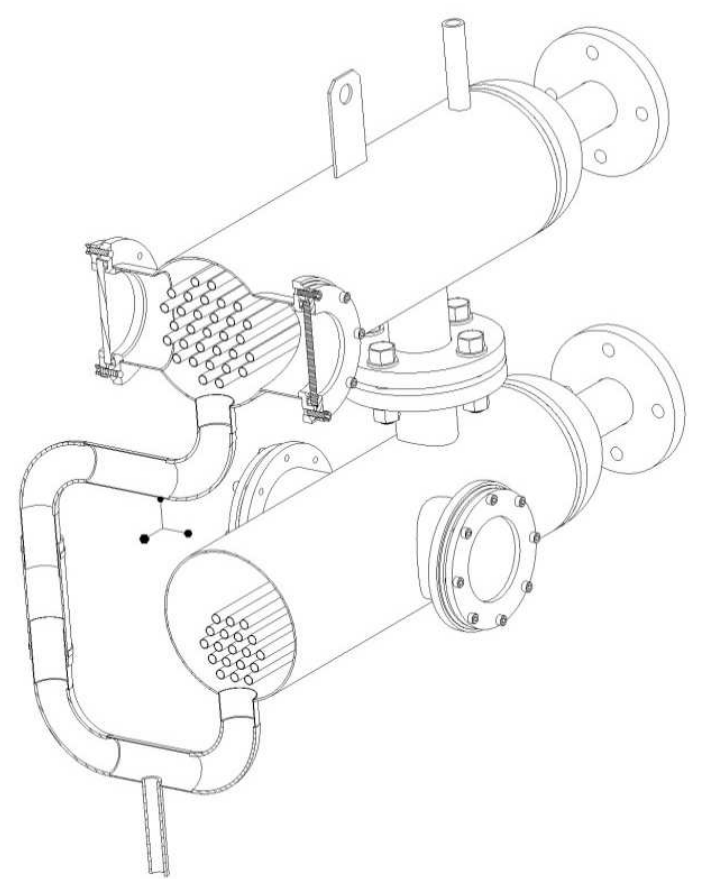

Figure 2: Axonometric view of the prototype TPTHEx.

shows photographs of the tested water- $\mathrm{Al}_{2} \mathrm{O}_{3}$ nanofluids after charge of the TPTHEx.

\subsection{Experimental procedure}

Before the tankage of the TPTHEx with working fluid an absolute pressure of $5 \mathrm{kPa}$ was created inside the shell. During the tests the absolute pressure inside the shell ranged from 5 to $20 \mathrm{kPa}$, which corresponds to the operating temperatures of $48{ }^{\circ} \mathrm{C}$ and $62{ }^{\circ} \mathrm{C}$. Heating as well as cooling water mass flow rates ranged from 0.3 up to $3.5 \mathrm{~kg} / \mathrm{s}$. The monitoring of the temperature and pressure readings was facilitated by the use of a $\mathrm{PC}$-aided data acquisition system. All data readings have been performed during steady-states. More details concerning experimental setup and procedure are presented in [24]. 


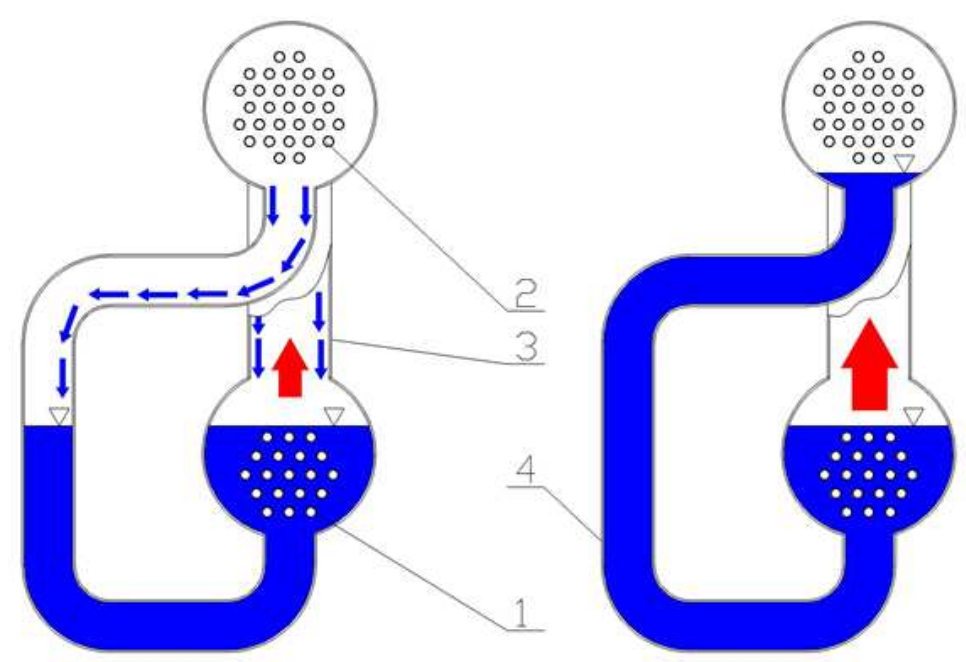

Figure 3: Liquid and vapour flow in TPTHEx: 1 - evaporator, 2 - condenser, 3 - riser, 4 - downcomer; left side picture - heat flux $\dot{q}<15 \mathrm{~kW} / \mathrm{m}^{2}$, right side picture $-\dot{q}>15 \mathrm{~kW} / \mathrm{m}^{2}$.

\subsection{Data reduction}

The overall heat transfer coefficient for the prototype TPTHEx can be estimated using the modified Peclet equation

$$
k_{e x p}=\frac{1}{\frac{A_{e v\left(\bar{t}_{h f}-t_{f}\right)}}{\dot{Q}_{e v}}+\frac{A_{c}\left(t_{f}-\bar{t}_{c f}\right)}{\dot{Q}_{c}}}
$$

where:

$\dot{Q}_{e v}$ - heat transfer rate transferred in the evaporator estimated using the measured volume flow rate of the hot water and the measured hot water temperatures at the inlet $t_{h f, 1}$ and outlet $t_{h f, 2}$

$$
\dot{Q}_{e v}=\dot{V}_{h f} \rho_{h f} c_{h f}\left(t_{h f, 1}-t_{h f, 2}\right) ;
$$

$\dot{Q}_{c}$ - heat transfer rate transferred in the condenser estimated using the measured volume flow rate of the cold water and the measured cold water temperatures at the inlet $t_{c f, 1}$ and outlet $t_{c f, 2}$

$$
\dot{Q}_{c}=\dot{V}_{c f} \rho_{c f} c_{p f}\left(t_{c f, 2}-t_{c f, 1}\right) ;
$$




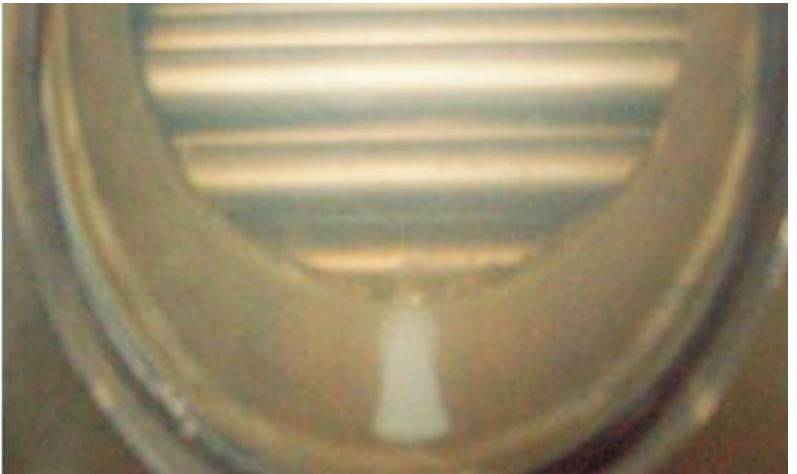

a)

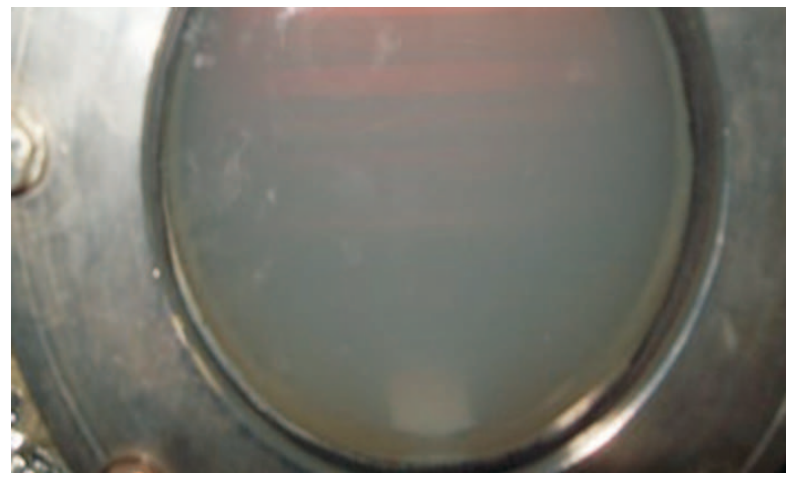

b)

Figure 4: Photographs of the tested water- $\mathrm{Al}_{2} \mathrm{O}_{3}$ nanofluids: a) $0.01 \%$ nanoparticle concentration, b) $0.1 \%$ nanoparticle concentration.

$\bar{t}_{h f}$ - arithmetic mean of the measured inlet and outlet hot fluid temperature

$$
\bar{t}_{h f}=\frac{t_{h f, 1}+t_{h f, 2}}{2} ;
$$

$\bar{t}_{c f}$ - arithmetic mean of the measured inlet and outlet cold fluid temperature

$$
\bar{t}_{c f}=\frac{t_{c f, 1}+t_{c f, 2}}{2}
$$

$t_{f}$ - arithmetic mean of the measured working fluid temperature

$$
t_{f}=\frac{t_{f 1}+t_{f 2}}{2}
$$


On the other hand the overall heat transfer coefficient for the prototype TPTHEx can be determined analyzing the thermal processes influencing transferred heat transfer rate. It was assumed that heat transfer performance of the TPTHEx results from the following heat transfer mechanisms:

- single phase convection inside evaporator's tube,

- heat conduction in the walls of the evaporator's tube,

- pool boiling outside evaporator's tube bundle,

- condensation outside condenser's tube bundle,

- heat conduction in the walls of the condenser's tube,

- single phase convection inside condenser's tube.

So, the overall heat transfer coefficient can be calculated as an inverse of the overall thermal resistance

$$
k_{W}=\frac{1}{R}=\frac{1}{R_{e v}+R_{c}}=\frac{1}{\frac{1}{k_{e v}}+\frac{1}{k_{c}}},
$$

where:

$k_{e v}$ - evaporator overall heat transfer coefficient

$$
k_{e v}=\frac{1}{\frac{1}{\alpha_{e v, i}}+\frac{\delta_{t}}{\lambda_{t}}+\frac{1}{\alpha_{e v, o}}}
$$

$k_{c}$ - condenser overall heat transfer coefficient

$$
k_{c}=\frac{1}{\frac{1}{\alpha_{c, i}}+\frac{\delta_{t}}{\lambda_{t}}+\frac{1}{\alpha_{c, o}}} .
$$

Heat transfer coefficients during boiling $\alpha_{e v, o}$, and condensation $\alpha_{c, o}$ were calculated as

$$
\alpha_{e v, o}=\frac{\dot{Q}_{e v}}{A_{e v} \Delta T_{e v}},
$$

and

$$
\alpha_{c, o}=\frac{\dot{Q}_{c}}{A_{c} \Delta T_{c}} .
$$


Mean evaporator fluid-to-wall temperature difference, so called wall superheat, $\Delta T_{e v}$, reads

$$
\Delta T_{e v}=t_{e v, o}-t_{f} .
$$

Mean condenser fluid-to-wall temperature difference reads

$$
\Delta T_{c}=t_{f}-t_{c, o} .
$$

The details of the $t_{e v, o}$ and $t_{c, o}$ calculations are given in [24].

Heat transfer coefficients during single phase convection inside tubes of the evaporator, $\alpha_{e v, i}$, and the condenser, $\alpha_{c, i}$, were determined by applying the Wilson plot technique [25]. The method is simple and has a wide potential for applications of different types of heat exchangers [26-31]. The classical Wilson plot method, as well as its modifications, requires only determination of the overall resistance in the heat exchanger and hence an accurate energy balance, based on measurement of flow rates of fluids exchanging heat and their mean temperature at inlet and outlet from heat exchanger. In present case heat transfer coefficient of hot water flowing inside evaporator tube, $\alpha_{e v, i}$, was calculated as

$$
\alpha_{e v, i}=\frac{1}{C_{3}-2 \frac{\delta_{t}}{\lambda_{t}}-\frac{1}{\alpha_{e v}}-\frac{1}{\alpha_{c}}} \text { for } \dot{m}_{h f}=\text { const. and } \dot{m}_{c f}=\text { var. }
$$

or

$$
\alpha_{e v, i}=\frac{1}{C_{2} w_{h}^{n}} \text { for } \dot{m}_{c f}=\text { const. and } \dot{m}_{h f}=\text { var . }
$$

Heat transfer coefficient of cold water flowing inside condenser tube, $\alpha_{c, i}$, was calculated as

$$
\alpha_{c, i}=\frac{1}{C_{2} w_{c}^{n}} \text { for } \dot{m}_{h f}=\text { const. and } \dot{m}_{c f}=\text { var. }
$$

or

$$
\alpha_{c, i}=\frac{1}{C_{3}-2 \frac{\delta_{t}}{\lambda_{t}}-\frac{1}{\alpha_{e v}}-\frac{1}{\alpha_{c}}} \text { for } \dot{m}_{c f}=\text { const. and } \dot{m}_{h f}=\text { var } .
$$

The constants $\mathrm{C}_{2}$ and $\mathrm{C}_{3}$ are Wilson method constants determined by use of linear regression [32], $w_{h f}$ and $w_{c f}$ are hot and cold water velocities, respectively. A pool boiling heat transfer coefficient $\alpha_{e v}$ was predicted by use of Cooper correlation [33] for distilled water and for water- $\mathrm{Al}_{2} \mathrm{O}_{3}$ nanofluids using Cieśliński and Kaczmarczyk data and correlation equation [34,35]. 
Condensation heat transfer coefficient $\alpha_{c}$ was calculated for distilled water and nanofluids from classical Nusselt correlation [36], and as results from Yang and Liu [12] study, it was a justified approach. The exponent $n$ in Eq. (15) and Eq. (16), dependent on flow regime, was assumed as equal to $n=0.8$ (turbulent flow).

\subsection{Error analysis}

The uncertainties of the measured and calculated parameters were estimated using the mean-square method. The maximum overall experimental heat flux error limits for the evaporator ranged from $\pm 1.4 \%$ (maximum heat flux) to $\pm 27 \%$ (minimum heat flux), while the average evaporator heat transfer coefficient maximum error was estimated at $\pm 27 \%$, and the wall superheat maximum error was estimated at $\pm 25 \%$.

\section{Results and discussion}

In order to validate experimental apparatus and procedure, present results obtained for distilled water as working fluid were compared to the data reported by Cieśliński and Fiuk [24] for the same configuration of the TPTHEx. Overall heat transfer coefficient in [24] was determined using modified Peclet equation (1). As it is seen in Fig. 5 satisfactory agreement has been obtained for operating pressure $12 \mathrm{kPa}$. However, for present data, the values of the overall heat transfer coefficient estimated using modified Peclet equation are lower than the values of the overall heat transfer coefficient predicted by applying the Wilson approach. The results were obtained for the case where $\dot{m}_{c f}=$ const. and $\dot{m}_{h f}=$ var .

Figure 6 shows boiling curves of the TPTHEx evaporator for three tested working fluids, i.e., distilled water and nanofluid water- $\mathrm{Al}_{2} \mathrm{O}_{3}$ with two nanoparticle concentrations: $0.01 \%$ and $0.1 \%$, for operating pressure inside a shell of about $3 \mathrm{kPa}$. Boiling curves for both nanofluids are shifted left towards lower wall superheat and decrease in nanoparticle concentration results in better performance of the tested TPTHEx. Present data are in agreement with previously obtained results for pool boiling of water- $\mathrm{Al}_{2} \mathrm{O}_{3}$ nanofluid on single tube [34].

Figure 7 illustrates the influence of operating pressure on TPTHEx evaporator performance for nanofluid water- $\mathrm{Al}_{2} \mathrm{O}_{3}$ with nanoparticle concentration $0.01 \%$. Decrease of absolute pressure from about 8 to $4 \mathrm{kPa}$ 


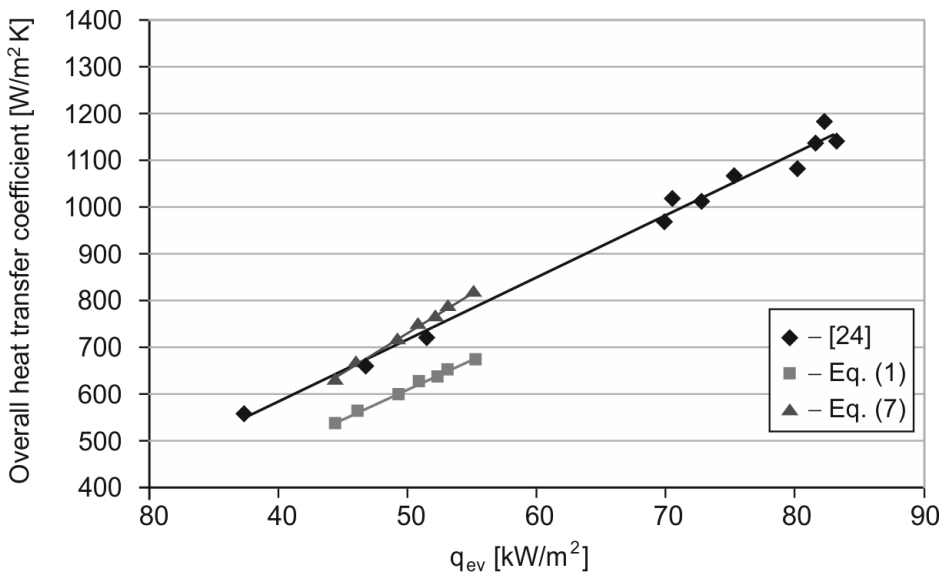

Figure 5: Overall heat transfer coefficient vs. evaporator heat flux for distilled water as working fluid at operating pressure inside shell of about $12 \mathrm{kPa}$.

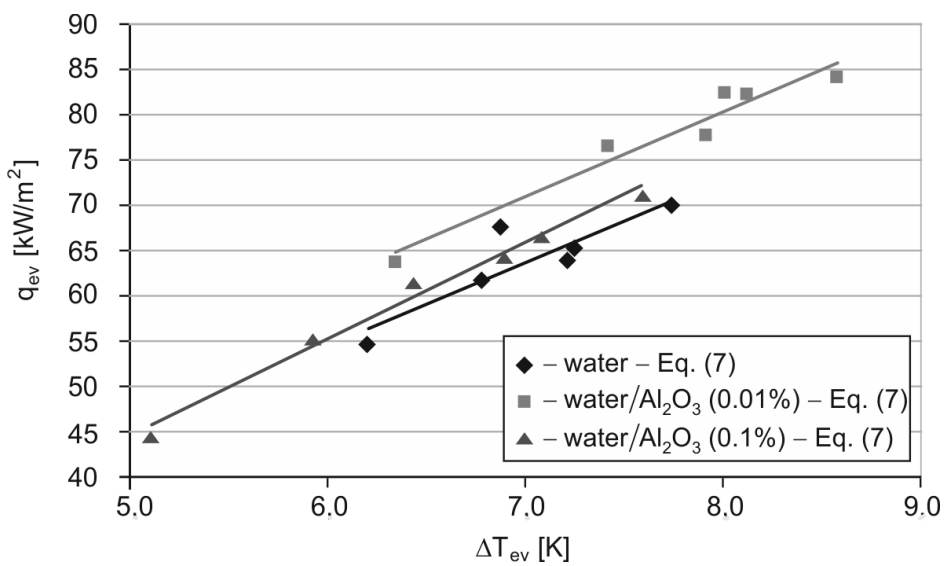

Figure 6: Boiling curves of the TPTHEx evaporator at operating pressure inside shell of about $3 \mathrm{kPa}$.

inside a shell results in distinct heat transfer augmentation. Obtained results confirm tendency observed in the literature [17,37].

Figures 8 and 9 illustrate effect of $\mathrm{Al}_{2} \mathrm{O}_{3}$ nanoparticle concentration on TPTHEx overall heat transfer coefficient (OHTC) for absolute pressure inside the shell of $10 \mathrm{kPa}$ and $4 \mathrm{kPa}$, respectively. Both methods of the OHTC estimation used in present study indicate that addition of nanoparticles results in higher OHTC in comparison with distilled water as working fluid. Additionally, increase in nanoparticle concentration causes decrease of the 


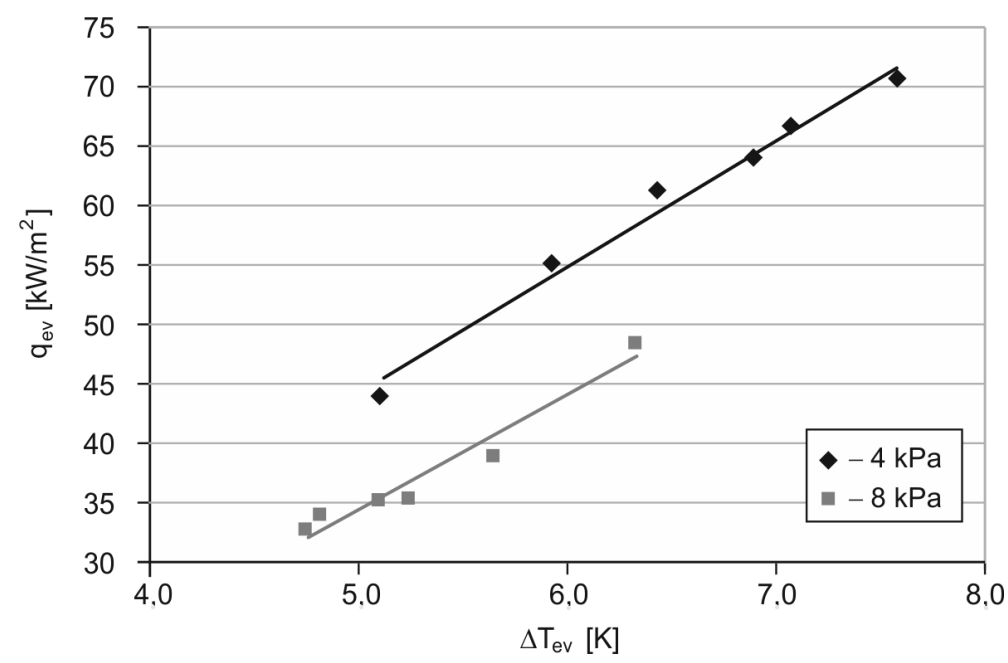

Figure 7: Influence of pressure on TPTHEx evaporator performance for nanofluid water$\mathrm{Al}_{2} \mathrm{O}_{3}$ with nanoparticle concentration $0.01 \%$.

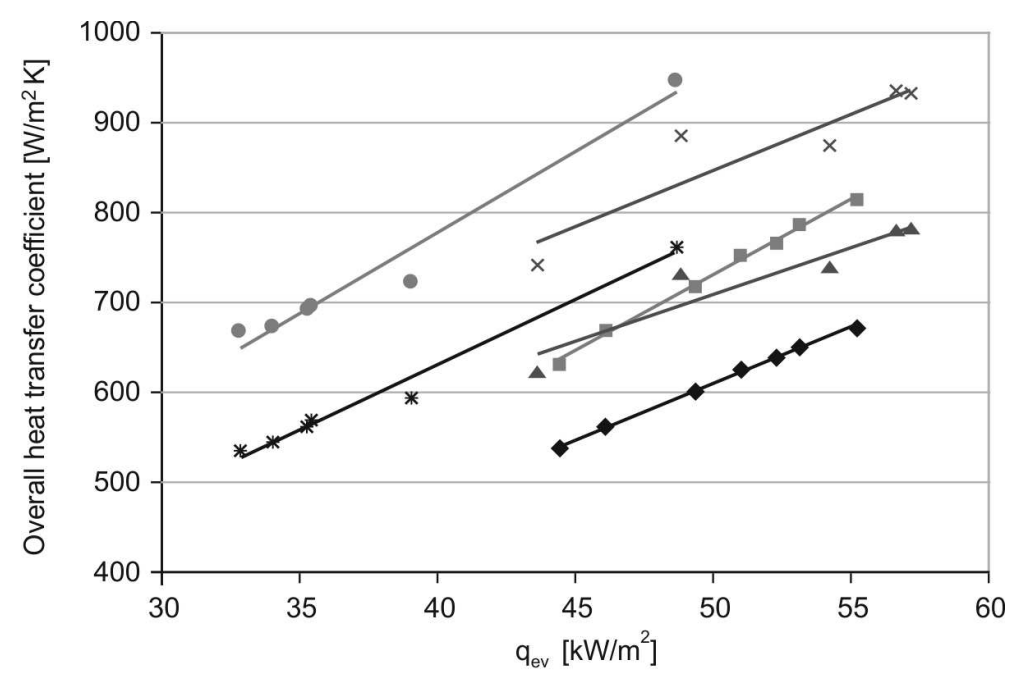

\begin{tabular}{|ll|}
\hline- - water - Eq. (1) & - -water $/ \mathrm{Al}_{2} \mathrm{O}_{3}(0.01 \%)-$ Eq. (7) \\
- - water - Eq. (7) & - -water $/ \mathrm{Al}_{2} \mathrm{O}_{3}(0.1 \%)-$ Eq. (1) \\
$*$ - water $/ \mathrm{Al}_{2} \mathrm{O}_{3}(0.01 \%)-$ Eq. (1) & $\times$-water $/ \mathrm{Al}_{2} \mathrm{O}_{3}(0.1 \%)-$ Eq. (7) \\
\hline
\end{tabular}

Figure 8: TPTHEx overall heat transfer coefficient vs. evaporator heat flux at operating pressure inside shell of about $10 \mathrm{kPa}$. 


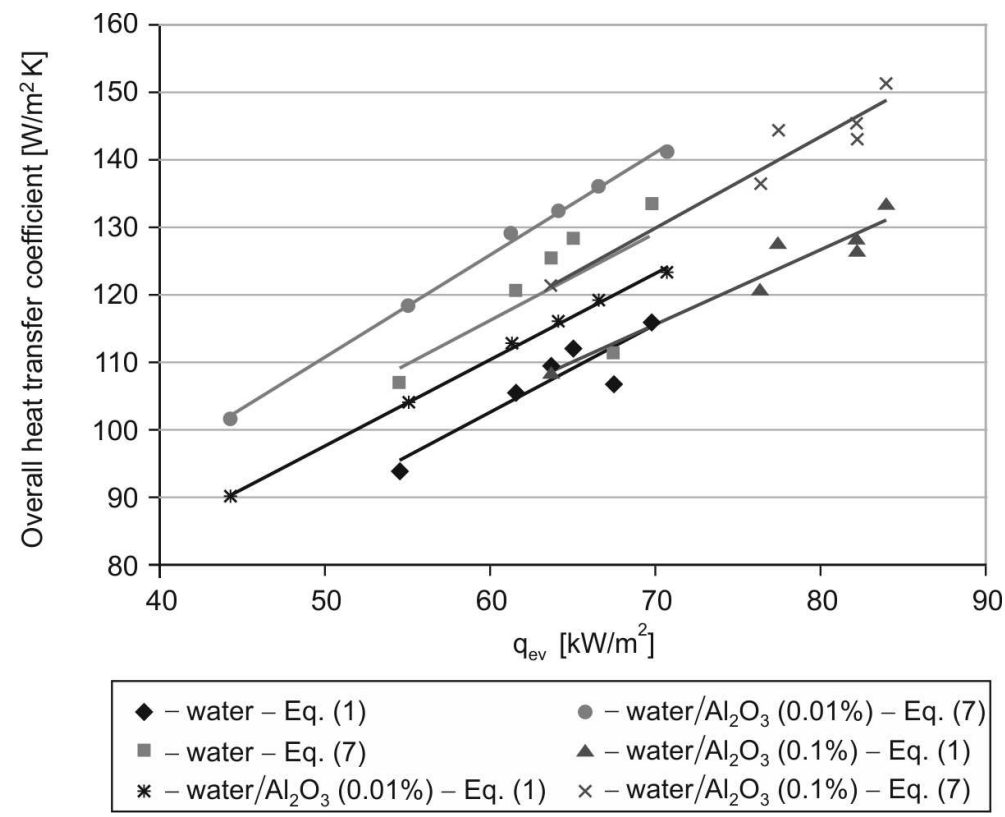

Figure 9: TPTHEx overall heat transfer coefficient vs. evaporator heat flux at operating pressure inside shell of about $4 \mathrm{kPa}$.

OHTC. Satisfactory agreement between the values of OHTC obtained by use of both proposed methods of data reduction. Nevertheless, Wilson approach Eq. (7) overestimates OHTC in comparison with method relied on energy balance Eq. (1), with maximum difference below $20 \%$, independent of the tested working fluid and operating pressure.

As an example Fig. 10 illustrates the effect of nanoparticle sedimentation on TPTHEx evaporator performance with nanofluid water- $\mathrm{Al}_{2} \mathrm{O}_{3}$ as working fluid with nanoparticle concentration of $0.1 \%$. Boiling curves for run just after tankage and after six days out of TPTHEx operation practically overlap. It proves that prepared nanofluids were stable.

\section{Conclusions}

- Addition of $\mathrm{Al}_{2} \mathrm{O}_{3}$ nanoparticles results in a higher overall heat transfer coefficient in comparison with pure water as working fluid.

- Increase in nanoparticle concentration causes a decrease of the overall heat transfer coefficient of the TPTHEx. 


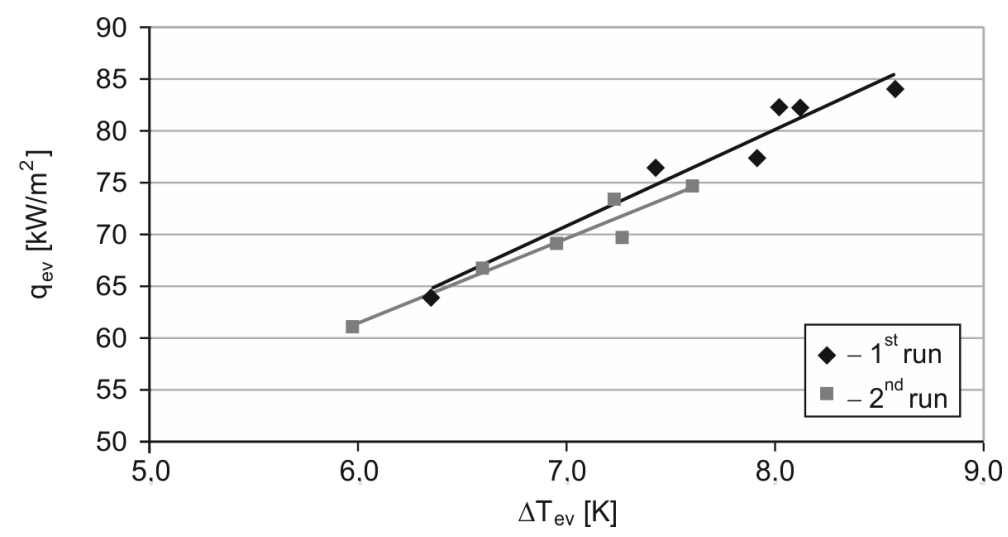

Figure 10: Effect of nanoparticle sedimentation on TPTHEx performance for water$\mathrm{Al}_{2} \mathrm{O}_{3}$ nanofluid as working fluid with nanoparticle concentration $0.1 \%$.

- Decrease of absolute pressure from about 8 to $3 \mathrm{kPa}$ inside a shell results in distinct heat transfer augmentation.

- Negligible effect of sedimentation on TPTHEx performance after six days out of operation was observed.

Acknowledgement The author wish to thank Jacek Rubalewski for his help with conduction of the experiments.

Received 12 February 2016

\section{References}

[1] Piono L.S., Piono I.L.: Industrial Two-Phase Thermosyphons. Begell House Inc. New York, Wallingford 1997.

[2] Gavotti N., PolášEk F.: Thermal control of electronic components by means of two-phase thermosyphons. In: Proc. Eurotherm Sem. Genoa 1999, No. 6, Single and Two-Phase Natural Circulation, 229-238.

[3] Bieliński H., Mikielewicz J.: Application of a two-phase thermosyphon loop with minichannels and a minipump in computer cooling. Arch. Thermodyn. 37(2016), 1, $3-16$.

[4] Zhang M., LiU Z., Ma G.: The experimental investigation on thermal performance of a flat two-phase thermosiphon. Int. J. Therm. Sci. 47(2008), 1195-1203.

[5] Khodabandeh R., Furberg R.: Heat transfer, flow regime and instability of a nano- and micro-porous structure evaporator in a two-phase thermosyphon loop. Int. J. Therm. Sci. 49(2010), 1183-1192. 
[6] He J., Lin G., Bai L., Miao J., Zhang H., Wang L.: Effect of non-condensable gas on steady-state operation of a loop thermosyphon. Int. J. Therm. Sci. 81(2014), 59-67.

[7] Kafeel K., Turan A.: Simulation of the response of a thermosyphon under pulsed heat input conditions. Int. J. Therm. Sci. 80(2014), 33-40.

[8] CHOI S.: Enhancing thermal conductivity of fluids with nanoparticles. Developments and applications of non-Newtonian flows. ASME, FED-Vol. 231/MD 66(1995), 99105.

[9] Pantzali M.N., Mouza A.A., Paras S.V.: Investigating the efficacy of nanofluids as coolants in plate heat exchanger (PHE). Chem. Eng. Sci. 64(2009), 3290-3300.

[10] Murshed S.M.S., Nieto De Castro C.A., Lourenc M.J.V., Lopes M.L.L., Santos F.J.V.: A review of boiling and convective heat transfer with nanofluids. Renew. Sustainable Energ. Rev. 15(2011) 2342-2354.

[11] Huminic G., Huminic A.: Heat transfer characteristics of a two-phase closed thermosyphons using nanofluids. Exp. Therm. Fluid Sci. 35(2011), 550-557.

[12] YANG X.F., LiU Z.H.: Application of functionalized nanofluid in thermosiphon. Nanoscale Res. Lett. 6(2011), 494 (1-12); http://www.nanoscalereslett. com/content/6/1/494

[13] Xue H.S., Fan J.R., Hu Y.C., Hong R.H., Cen K.F.: The interface effect of carbon nanotube suspension on the thermal performance of a two-phase closed thermosiphon. J. Appl. Phys. 100(2006), 104909.

[14] Mehta B., Khandekar S.: Two-phase closed thermosyphon with nanofluids. In: Proc. 14th Int. Heat Pipe Conf., Florianopolis 2007, 22-27.

[15] Khandekar S., Joshi Y.M., Menta B.: Thermal performance of closed two-phase thermosyphon using nanofluids. Int. J. Therm. Sci. 47(2008), 659-667.

[16] Noie S.H., Zeinali Heris S., Kahani M., Nowee S.M.: Heat transfer enhancement using $\mathrm{Al}_{2} \mathrm{O}_{3} /$ water nanofluid in a two-phase closed thermosyphon. Int. J. Heat and Fluid Flow 30(2009), 700-705.

[17] Liv Z.H., YAng X.F., Wang G.S., Guo G.I.: Influence of carbon nanotube suspension on the thermal performance of a miniature thermosiphon. Int. J. Heat Mass Tran. 53(2010), 1914-1920.

[18] Parametthanumat T., Rittidech S., Pattiya A.: A correlation to predict heattransfer rates of a two-phase closed thermosyphon (TPCT) using silver nanofluid at normal operating conditions. Int. J. Heat Mass Tran. 53(2010), 4960-4965.

[19] Paramatthanumat T., Boothaisong S., Rittidech S., Booddachan K.: Heat transfer characteristics of a two-phase closed thermosyphon using de ionized water mixed with silver nano. Heat Mass Tran. 46(2010), 281-285; doi 10.1007/s00231009-0565-y

[20] Huminic G., Huminic A., Morjan I., Dumitrache F.: Experimental study of the thermal performance of thermosyphon heat pipe using iron oxide nanoparticles. Int. J. Heat Mass Tran. 54(2011), 656-661.

[21] Firouzfar E., Soltanieh M., Noie S.H., Saidi S.H.: Energy saving in HVAC systems using nanofluid. Appl. Therm. Eng. 31(2011), 1543-1545. 
[22] Buschmann M.H.: Nanofluids in thermosyphons and heat pipes: Overview of recent experiments and modelling approaches. Int. J. Therm. Sci. 72(2013), 1-17.

[23] Cieśliński J.T., Fiuk A.: Thermosyphon Heat Exchanger. Polish Patent PL 192757, 2006.

[24] Cieśliński J.T., Fiuk A.: Heat transfer characteristics of a two-phase thermosyphon. Appl. Therm. Eng. 51(2013), 112-118.

[25] Wilson E.E.: A basis for rational design of heat transfer apparatus. Trans. ASME 37(1915), 47-82.

[26] Briggs D.E., Young E.H.: Modified Wilson plot techniques for obtaining heat transfer correlations for shell and tube heat exchangers. AIChE Symp. Ser. 65(1969), $35-45$.

[27] Sнан R.K.: Assessment of modified Wilson plot techniques for obtaining heat exchanger design data. In: Proc. 9th Int. Heat Transfer Conf., Jerusalem 1990, 5(1990), $51-56$.

[28] Fernandez-Seara J., Uhia F.J., Sieres J., Campo A.: A general review of the Wilson plot method and its modifications to determine convection coefficients in heat exchange devices. Appl. Therm. Eng. 27(2007), 2745-2757.

[29] Shokouhmand H., Salimpour M.R., Akhavan-Behabadi M.A.: Experimental investigation of shell and coiled tube heat exchangers using Wilson plots. Int. Comm. Heat Mass Tran. 35(2008), 84-92.

[30] van Rooyen E., Cristians M., Thome J.R.: Modified Wilson plots for enhanced heat transfer experiments: Current status and future perspectives. Heat Tran. Eng. 33(2012), 342-355, doi:10.1080/01457632.2012.611767

[31] Mikielewicz D., Wajs J., Mikielewicz J.: Determination of heat transfer coefficient in evaporator of the ORC using the Wilson method. In: Proc. XVII Int. Conf. Heat Transfer and Renewable Sources of Energy, Szczecin-Międzyzdroje 2008, 489-496.

[32] Cieśliński J.T., Rubalewski J.: Determination of the overall heat transfer coefficient for the two-phase thermosyphon heat exchanger. Technika Chłodnicza i Klimatyzacyjna 195(2012), 5, 206-211 (in Polish).

[33] Cooper M.G.: Heat flow in saturated nucleate pool boiling - A wide-ranging examination using reduced properties. Adv. Heat Tran. 16(1984), 157-239.

[34] Cieśliński J.T., Kaczmarczyk T.Z.: Pool boiling of water- $\mathrm{Al}_{2} \mathrm{O}_{3}$ and waterCu nanofluids on horizontal smooth tubes. Nanoscale Res. Lett. 6(2011), 220(1-9), doi:10.1186/1556-276X-6-220 - ISSN 1556-276X

[35] Cieśliński J.T., Kaczmarczyk T.Z.: Pool boiling of nanofluids on rough and porous coated tubes: Experiment and correlation. Arch. Thermodyn. 35(2014), 2, $3-20$.

[36] Incropera F.P., Bergman T.L., Lavine A.S.: Fundamentals of Heat and Mass Transfer. 6th Edn., Wiley \& Sons, 2010.

[37] Cieśliński J.T., KaCZMarczyK T.Z.: The effect of pressure on heat transfer during pool boiling of water- $\mathrm{Al}_{2} \mathrm{O}_{3}$ and water-Cu nanofluids on stainless steel smooth tube. Chem. Process Eng. 32(2011), 4, 321-332. 